\title{
Analysis and Exploration on the Current Situation of College Students' Online Credit: Taking G University as an Example
}

\author{
Xudong Wang* \\ Guangdong Ocean University, Zhanjiang 524088, Guangdong Province, China \\ *Corresponding author: Xudong Wang, Wangxudong8686@126.com
}

\begin{abstract}
With the continuous development of Internet finance, online consumption is becoming a trend among a growing number of college students but at the same time, the risk of online consumption is also gradually becoming more apparent. Colleges and universities are susceptible to frequent credit consumption risk events such as "campus loan." This paper focuses on the relevant influencing factors and characteristics of consumption behavior in college students under the background of the era of Internet finance. This paper presents an analysis based on 303 sample collected from G University. It is found that the online credit products come from a wide range of sources and are highly accepted by college students. Consumption patterns are diversified. Most of them can be treated rationally, but the students' repayment ability is limited. In this regard, colleges and universities, families and the government should strengthen cooperation in order to guide college students to establish a rational concept of consumption.
\end{abstract}

Keywords: College student; Credit products; Irrational consumption

Publication date: December 2021; Online publication: January 24, 2022

\section{Introduction}

With the rapid development of the Internet economy, Internet credit consumption has become an important consumption mode of college students. In recent years, consumer finance in China has developed rapidly, especially the growth of short-term consumer loans. According to the data, by the end of 2019, the balance of personal short-term consumer loans was 9.9 trillion yuan, corresponding to a year-on-year increase of $12.7 \%$ [1], which is a $>1.4$-fold increase of 4.1 trillion yuan at the end of 2015. As an important group of short-term consumer loans, college students' network credit consumption is becoming more and more common. At the same time, college students especially those born after 2000 have strong curiosity and low purchasing power but are willing to try to purchase and borrow on credit ${ }^{[2]}$. There are many problems that need to be solved. Therefore, the investigation of college students' online credit problems is helpful to explore the influencing factors of online credit consumption and provide reasonable suggestions for the effective governance of online credit.

\section{Research subjects and method}

In this study, the students of G University were recruited as research subjects. Through distribution of online questionnaires, 450 questionnaires were sent out, and 303 valid questionnaires were recovered, with an effective recovery rate of $67.3 \%$. Among them, the percentages of boys and girls were $67 \%$ and $43 \%$, respectively. According to the gender and grade of the respondents, freshmen account for $8.1 \%$, sophomores $43.32 \%$, junior students $40.08 \%$, and senior students $8.5 \%$. In addition, the questionnaire 
mainly includes the basic information of the research subjects, the cognition of the online credit platform, the sources and living expenses, and the use and repayment of online credit products.

\section{Basic situation of online credit platform consumption among college students}

\subsection{High consumption by some college students giving way to the existence of online credit}

As shown in Figure 1, the survey and analysis results show that the living expenses of most students are about $1000-1500$ yuan, accounting for $67.32 \% ; 16.00 \%$ at $1500-2000$ yuan; $13.60 \%$ below 1000 yuan; and less than 2000 yuan at only $3.07 \%$. In terms of monthly expenditure, $56.58 \%$ and $19.30 \%$ of those with expenditure between 1000-1500 and below 1000, respectively, and $19.74 \%$ and $4.38 \%$ of those with expenditure above 1500-2000 and 2000, respectively. Some groups show a high consumption trend. However, according to the cost of living of 25 yuan per day, the monthly cost of living is about 750 yuan. However, the students' expenditure is spent on living, learning and training, electronic consumption, etc. The basic living expenditure accounts for $50 \%$ of the total living expenses. It shows that at present, college students' expenses are increasing, but their income is greater than consumption, which is different from the actual living expenses of college students, providing the ground for the spread of network credit in colleges and universities.

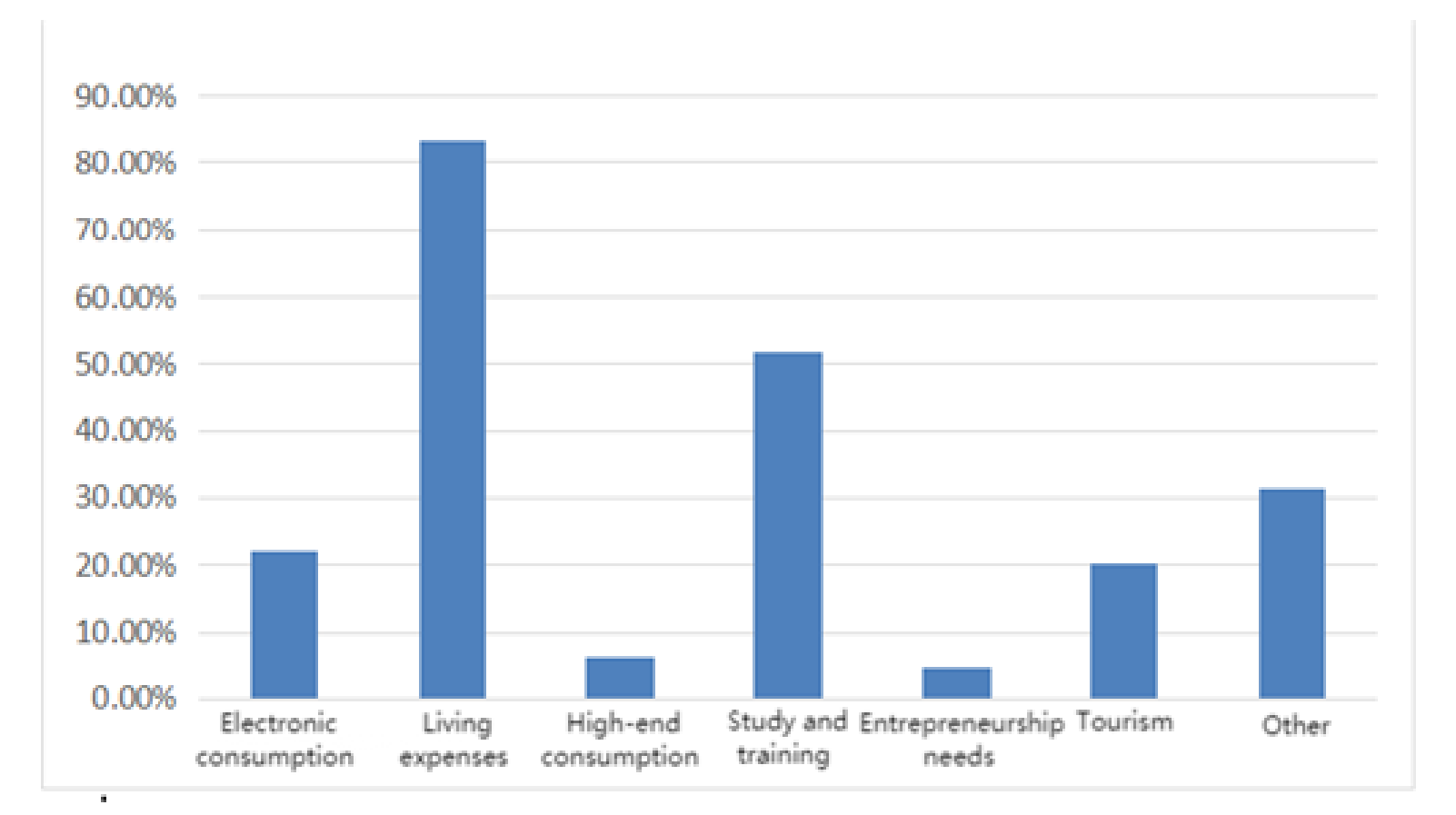

Figure 1. Columnar statistical chart of living expenses distribution of students in G University

\subsection{Online credit products from a wide range of sources and the varying number of years of usage}

As shown in Figure 2, the survey results show that in terms of the sources of online credit products, mobile software promotion, friend recommendation and personal discovery account for more than $25 \%$, while other sources are relatively few, showing a trend of online and offline. In terms of the use of online credit products, $62.28 \%$ of the students said they had used credit products, of which $52.81 \%$ said they had used credit products for about one year; $25.08 \%$ of the students have used credit software for about 2 years; students who have used it for more than 2 years accounted for $14.52 \%$, and only $7.6 \%$ said that they had used it for less than half a year. This shows that the usage of credit software is very common among college students. 


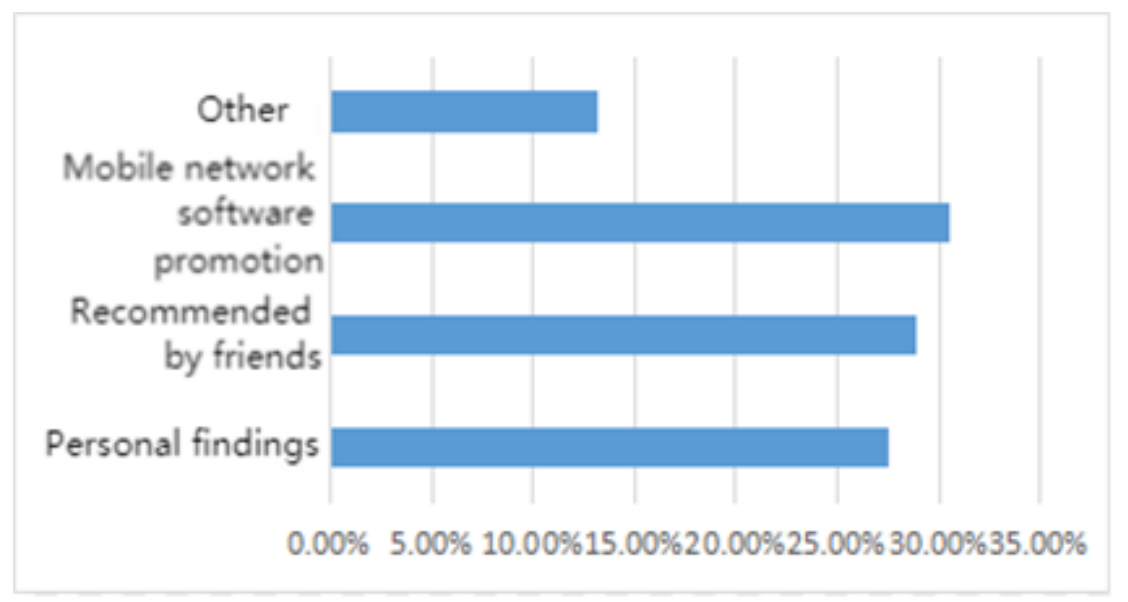

Figure 2. Columnar statistical chart of distribution of G University’s access to credit products

\subsection{Limited repayment ability despite a rational attitude towards online credit}

Among the respondents, $61.13 \%$ of the students agreed to use credit products for advanced consumption, and $59.11 \%$ believed that the advantages of lending tools outweighed the disadvantages. College students disputed the use of online credit products and held a critical attitude towards online credit products. The survey shows that after using credit tools, more than $50 \%$ of students' monthly consumption increases. Some students cannot control their expenses after using loan tools, which is related to the fact that the use of credit platform will reduce the sensitivity of merchants to commodity prices. The survey results show that when using the consumer lending platform for payment, $65.99 \%$ of the students said that they were unaware of the spending of money, and only $34.01 \%$ of the students remained rational about the price of goods. This phenomenon is also reflected that $11 \%$ of the students often consume in advance or cannot control their expenses at all. At the same time, nearly half of the students can use credit products according to their ability to pay, and $46.96 \%$ of the students can generally control their expenses. Most of the students pay more attention to the repayment time, $57.89 \%$ of them choose to repay if they have money, $18.62 \%$ of them repay automatically when due, and $23.48 \%$ of them repay the principal and interest by installments. However, more than $20 \%$ of students have defaulted. Interestingly, most students avoid letting their parents know that they use credit software. Repayment methods mainly include borrowing money from other students as well as using money reserved for saving and living expenses, which account for $53.85 \%$ and $58.7 \%$, respectively. Some students also make money for repayment through part-time jobs. Some students will turn to their parents for help.

\section{Analysis on the causes of widespread application of online loan credit among college students}

The widespread application of online credit among college students is affected by various factors such as social values, financial system, universities and families, which collectively gives way to the birth of online credit.

\subsection{Stimulation of pluralistic values and consumerism}

With the continuous development of market economy, values such as money worship, consumerism and hedonism spread in society, and imperceptibly affect the values and consumption concepts of college students. Some online consumption platforms encourage consumption in advance, which virtually speeds up the erosion of college students' consumption behavior by the wrong trend of thought of advanced consumption. It leads some students to indulge in hedonism, which provides a living ground for the 
widespread application of online credit in colleges and universities.

\subsection{Imperfect financial system}

The rapid development of network provides an opportunity for the emergence of online finance. It has gained traction of a majority of consumers because of its simple operation and fast update speed. However, at the same time, online finance and innovation continue to break through the institutional framework of traditional finance, resulting in the diversified development of online finance. The loopholes of network regulatory institutions and regulatory systems have created opportunities for the "barbaric" development of online credit and promoted the spread of online credit in colleges and universities.

\subsection{Lack of relevant consumption education in colleges and universities}

The network has been fully integrated into the study and life of college students, bringing much conveniences for them. As important places for cultivating talents, colleges and universities focus on students' learning of classroom knowledge, ideology and morality, but a lack of guidance on students' consumption concept and the popularization of relevant financial and credit knowledge may result in erratic consumption.

\subsection{Impact on personal and family environment}

Family plays an irreplaceable role in the formation and cultivation of college students' values ${ }^{[3]}$. Before entering the university, students' desire for money is rather subtle. Parents place a lot of emphasis on their children's learning process but neglect their outlook on money and consumption. After entering the university, some students begin the path of blind pursuit of pleasure and materials, resulting in the conception of abnormal consumption views, which affect the formation of normal consumption concept.

\section{Countermeasures on limiting college students' online credit}

With the advent of the Internet age, online credit products such as "ant flower chant" and "Jingdong Baitiao" have adapted to the advanced consumption behavior of college students. However, because college students do not have the ability to repay themselves and have not yet established a correct concept of consumption, there are some problems to be solved urgently, which require schools, families and society to adopt a linkage mechanism to create a good consumption environment.

\subsection{University level: Strengthen guidance and establish a rational concept of consumption}

Colleges and universities should constantly adapt to the development of the Internet era and pay attention to the dissemination of online credit information among college students. First, ideological and political education can be used to help college students establish correct values and consumption views, and cultivate rational and appropriate consumption ideas. Certain courses can be set up to strengthen publicity and education. Online credit security education can be strengthened and risk prevention awareness of college students can be enhanced through elective courses, class activities and other ways. Second, the prevention mechanism of network credit in colleges and universities should be improved. Big data can also be adopted to timely grasp the financial consumption and online credit of key students in order to carry out targeted intervention. In addition, online loan risk and independent thinking ability can be strengthened too ${ }^{[4]}$.

\subsection{Family level: Actively cooperate and establish an information communication mechanism}

Family education plays an important role in laying a foundation for children's life and preventing students 
from getting too deep into online credit debts. On the one hand, as parents, we should cultivate students' consumption concept from an early age, live within our means, and cultivate a rational consumption view. At the same time, students should be educated to carefully identify various online consumer products and avoid getting themselves as victims of online fraud. On the other hand, parents should establish a communication mechanism with colleges and universities to regularly learn about students' consumption during school, and timely check abnormal consumption to prevent "campus loan," "routine loan" and other behaviors.

\subsection{Government level: Strengthen supervision and standardize the operation of network platform}

The rapid development of Internet finance requires the government to implement an effective regulatory system. Excessive disorder and lack of supervision have a serious impact on college students' consumption concept, study and life. The government should establish a perfect regulatory mechanism for the online credit platform, and first of all, improve the "threshold" of the online credit platform. It is necessary to make detailed provisions on the capital source of the network platform and the setting of network credit products so as to improve the credit of the network credit platform. On this basis, government should timely issue the rules and regulations on the network credit platform and build the network credit mechanism. Secondly, government should strictly control the flow of funds. When issuing loans to students, the online credit platform should review the amount and objective of funds, and build an accurate assistance mechanism. In addition, we should guide the online credit platform how to legally stimulate the consumption of college students, provide high-quality online credit products, actively help college students in science and innovation competitions, learning and consumption, and cultivate a positive online consumption environment.

\section{Funding}

The Student Work Project of Guangdong Ocean University "Exploration and Construction of the Quality Evaluation System of Educational Quality in Colleges and Departments" [gdou201901]

\section{Disclosure statement}

The author declares that there is no conflict of interest.

\section{References}

[1] Central Bank of the People's Republic of China, Central Bank: In 2019, the Balance of Various RMB Loans of Financial Institutions was 153.11 Trillion Yuan. China Economic Net, released on January 23, 2020. http://finance.ce.cn/bank12/scroll/202001/23/t20200123_34182514.shtml

[2] Chen Y, 2021, Thoughts and Countermeasures Caused by College Students' Bad Campus Network Loan After “00”. University Logistics Research, 2021(2): 64-66.

[3] Xie X, 2021, Research on Risk Prevention and Educational Guidance Countermeasures of Bad Campus Online Loan. Journal of Hubei University of Science and Technology, 41(2): 31-34.

[4] Zhang J, 2021, Research on Problems and Countermeasures of Online Loan Safety Education for College Students. Journal of Huainan Vocational and Technical College, 21(3): 114-116. 